\title{
ROLE OF VARIOUS IMAGING MODALITIES AFTER A FIRST FEBRILE URINARY TRACT INFECTION IN YOUNG CHILDREN
}

\author{
Khalid Mohi-uddin Kawoosa ${ }^{1}$, Syed Wajid Ali2, Syed Heena Kubran ${ }^{3}$
}

${ }_{1}^{1}$ Senior Resident, Department of Paediatrics, SKIMS, Srinagar. Jammu and Kashmir.

2 Professor and HOD, Department of Paediatrics, SKIMS, Srinagar, Jammu and Kashmir.

${ }^{3}$ Senior Resident, Department of Ophthalmology, SKIMS, Srinagar, Jammu and Kashmir.

\section{BACKGROUND}

ABSTRACT

UTI in the paediatric population is well-recognised as the cause of acute morbidity and chronic medical conditions such as hypertension and renal insufficiency in adulthood. ${ }^{1}$ The goal of imaging studies in children with UTI is to identify anatomic abnormalities that predispose to infection, determine whether there is active renal involvement and to assess whether renal function is normal or at risk.

Aims and Objectives-

- $\quad$ To measure the incidence of renal scarring in patients admitted with first febrile UTI.

- To list renal image findings in patients with first febrile UTI, 1 - 36 months of age.

\section{MATERIALS AND METHODS}

A total of 108 patients, 1 - 36 months of age, coming with first febrile UTI, either admitted or on an outpatient department basis during one and a half years, who satisfy the inclusion criteria were studied. Renal scanning with technetium-99m labeled dimercaptosuccinic acid and renal ultrasonography were performed in the acute phase to determine the presence or absence of acute pyelonephritis and anatomical abnormalities, respectively. Contrast voiding cystourethrography was performed approximately one month after diagnosis in those with abnormal ultrasound or abnormal DMSA. Technetium-99m labeled dimercaptosuccinic acid renal scanning was repeated six months later to determine the incidence and severity of renal scarring. Age groups, sex, VCUG, renal ultrasonography and DMSA renal scintigraphy results were analysed.

\section{RESULTS}

Out of 108 patients, RBUS was normal in 63 (58\%) and abnormal in 45 (42\%). Sonogram showed changes consistent with acute pyelonephritis in $27.7 \%$ (30/108) of the whole group and in only $57.7 \%$ (30/52) of the patients with scintigraphically documented acute pyelonephritis. DMSA was suggestive of acute pyelonephritis in 52 (48\%) patients in acute stage and of renal scarring in 22 $(20 \%)$ at 6 months. All patients who had scarring at 6 months had abnormal initial scan. Out of 69 patients with abnormal ultrasonography or scanning who were subjected to VCUG, 39 had vesicoureteral reflux (56.5\%). Renal scarring was more likely to occur in children with documented VUR than those without VUR (17/39 vs. 5/30). Among the patients with VUR, scarring was seen more likely in patients with higher grades of VUR.

\section{CONCLUSION}

The renal ultrasound is of limited value in febrile UTI, especially at places where DMSA scanning is available. The use of DMSA during acute illness identifies patients with acute pyelonephritis who are at risk of development of renal scarring later in life. VCUG may demonstrate a relationship between VUR and renal inflammation and identify high-risk group for development of renal scarring.

\section{KEYWORDS}

Urinary Tract Infection, VUR, DMSA Scan.

HOW TO CITE THIS ARTICLE: Kawoosa KM, Ali SW, Kubran SH. Role of various imaging modalities after a first febrile urinary tract infection in young children. J. Evolution Med. Dent. Sci. 2018;7(11):1404-1408, DOI: 10.14260/jemds/2018/319

\section{BACKGROUND}

UTI in the paediatric population is well-recognised as a cause of acute morbidity and chronic medical conditions such as hypertension and renal insufficiency in adulthood. ${ }^{1}$ The goal of imaging studies in children with UTI is to identify anatomic abnormalities that predispose to infection,

'Financial or Other Competing Interest': None.

Submission 22-01-2018, Peer Review 27-02-2018,

Acceptance 05-03-2018, Published 12-03-2018.

Corresponding Author:

Khalid Mohi-uddin Kawoosa,

Omer Colony, Lal Bazar,

Srinagar.

E-mail: syedheenak@gmail.com

DOI: $10.14260 /$ jemds $/ 2018 / 319$ determine whether there is active renal involvement and to assess whether renal function is normal or at risk. ${ }^{1}$ The algorithm for the radiographic evaluation of children with febrile urinary tract infection is hotly debated. Three imaging modalities are commonly administered: renal-bladder ultrasound (RUS), voiding cystourethrogram (VCUG) and dimercaptosuccinic acid scan. ${ }^{2}$

\section{Aims and Objectives}

- To measure the incidence of renal scarring in patients admitted with first febrile UTI.

- To list renal image findings in patients with first febrile UTI, 1 - 36 months of age. 


\section{MATERIALS AND METHODS}

This study was conducted in the Postgraduate Department of Paediatrics, SKIMS, Srinagar for a period of two years (from November 2013 to November 2015).

\section{Inclusion Criteria}

Patients were enrolled if they met the following criteria: Rectal temperature of at least $38.3^{\circ} \mathrm{C}$ at presentation or within 24 hours and if a urinary tract infection is suspected. The presence of pyuria (10 or more white cells per cubic millimetre in uncentrifuged urine). Bacteriuria (1 or more gram-negative rods per 10 oil-immersion fields in a Gramstained smear of uncentrifuged urine). A positive urine culture (at least 50,000 colony-forming units per millilitre, representing a single pathogen) from a specimen obtained by suprapubic aspiration.

\section{Exclusion Criteria}

Patients were excluded from the study if they had history of previous episodes of UTI and Pyelonephritis or evidence of renal scarring in DMSA scan in acute phase.

A total of 108 patients 1 - 36 months coming with first febrile UTI, either admitted or on an outpatient department basis during one and a half year who satisfy the inclusion criteria were studied. All patients aged between $1-36$ months with first febrile UTI who fulfilled the inclusion criteria were evaluated by ultrasound and dimercaptosuccinic acid [DMSA] scintigraphy scan in the acute phase. In those patients with normal ultrasound and normal dimercaptosuccinic acid [DMSA] scintigraphy scan, rescanning was done at 6 months. Those with abnormal ultrasound or abnormal dimercaptosuccinic acid [DMSA] scintigraphy scan underwent voiding cystourethrography and due follow-up and rescanning was done 6 months later.

\section{Imaging Studies}

Renal scanning with technetium-99m labeled dimercaptosuccinic acid and renal ultrasonography were performed in the acute phase to determine the presence or absence of acute pyelonephritis and anatomical abnormalities, respectively. ${ }^{3}$ Renal ultrasound was considered normal if bilateral kidneys were normal and there was no evidence of dilatation of pelvicalyceal system. Hydronephrosis was graded as-

\section{Grade 0}

No dilatation, calyceal walls are opposed to each other.

\section{Grade 1}

(Mild) Dilatation of the renal pelvis without dilatation of the calyces (can also occur in the extrarenal pelvis). No parenchymal atrophy.

\section{Grade 2}

(Mild) Dilatation of the renal pelvis (mild) and calyces (Pelvicalyceal pattern is retained). No parenchymal atrophy.
Grade 3

(Moderate) dilatation of the renal pelvis and calyces. Blunting of fornices and flattening of papillae. Mild cortical thinning may be seen.

\section{Grade 4}

(Severe/ Gross) dilatation of the renal pelvis and calyces, which appear ballooned. Loss of borders between the renal pelvis and calyces renal atrophy is seen as cortical thinning. ${ }^{4}$

Contrast voiding cystourethrography was performed approximately one month after diagnosis, in those with abnormal ultrasound or abnormal DMSA. Vesicoureteral reflux was graded according to the classification system of the International Reflux Study Committee; grade I indicates reflux into the proximal ureter without dilatation, grade II reflux into the distal ureter without dilatation and grades III, IV and $V$ reflux into the distal ureter with mild, moderate and severe dilatation, respectively. ${ }^{5}$

Technetium-99m labeled dimercaptosuccinic acid renal scanning was repeated six months later to determine the incidence and severity of renal scarring. ${ }^{3}$

\section{Definitions}

Technetium-99m labeled dimercaptosuccinic acid scans were considered normal if homogeneous uptake of the radioisotope was evident throughout the kidneys and the renal contour was preserved.

Acute pyelonephritis was defined by the presence of focal or diffuse areas of decreased uptake of labeled dimercaptosuccinic acid without evidence of cortical loss or by the presence of diffusely decreased uptake in an enlarged kidney.

Renal scarring was defined by the presence of decreased uptake of labeled dimercaptosuccinic acid associated with loss of the contours of the kidney or by the presence of cortical thinning with decreased volume. ${ }^{3}$

\section{Statistical Methods}

The interpretation of results was done using Fisher and chisquare tests. SPSS (version 20.0) and Microsoft Excel were used for carrying out the statistical analysis of the data.

\section{Long-Term Follow-Up}

The children were followed for six months. Urine cultures were obtained at the time of most febrile illnesses. A history of fever or other signs or symptoms compatible with urinary tract infection was elicited during interim visits.

Age groups, sex, VCUG, renal ultrasonography and DMSA renal scintigraphy results were analysed. Before study enrolment, a written consent was required from the parent (s) for all patients. Institutional ethics approval was obtained prior to the study.

\section{RESULTS}

A total of 108 children in the age group of 1 - 36 months were included. $47.2 \%$ (51 patients) were males and 52.8\% (57 patients) were females. 


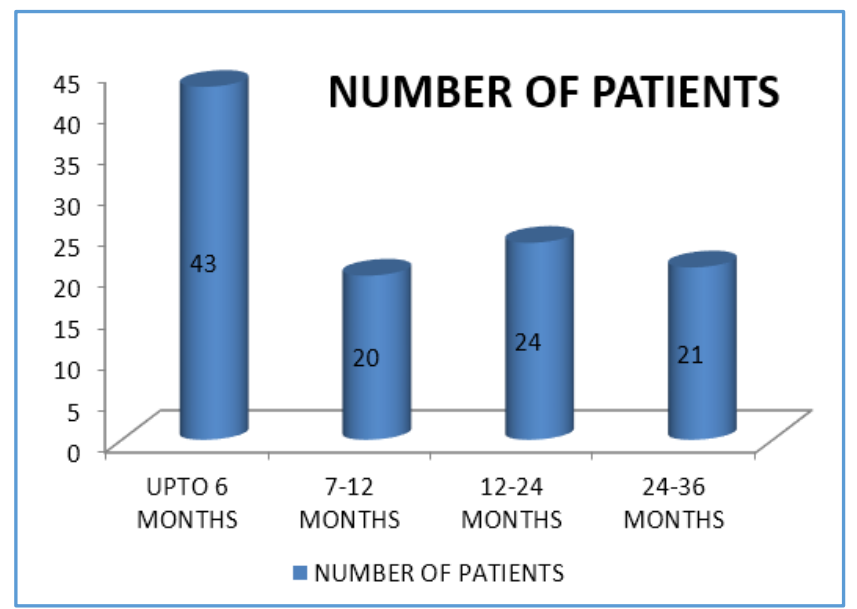

Figure 1. Age Distribution of Patients with First Febrile UTI

All patients following first febrile UTI were evaluated using an initial technetium 99m-labeled dimercaptosuccinic acid scintigram and a renal ultrasonogram within the first week of diagnosis. Of 108 ultrasonograms 63 (58\%) were normal, the rest being abnormal as shown in Table 1 . Thirty seven patients had findings suggestive of hydronephrosis (34.2\%). The initial dimercaptosuccinic acid scan showed that 52 out of 108 children (48.1\%) had findings suggestive of acute pyelonephritis. The total number of patients with acute pyelonephritis having ultrasonographic abnormalities associated were 30 ( $57.7 \%$ of total 52 patients).

\begin{tabular}{|c|c|c|}
\hline Findings & No. of Renal Units & No. of Patients \\
\hline Dilated pelvis & 12 & 7 \\
\hline Absent kidney & 1 & 1 \\
\hline HDN Gr I & 9 & \\
Gr II & 16 & 37 \\
Gr III & 18 & \\
Gr IV & 7 & 63 \\
\hline Normal & 153 & \\
\hline Table 1. USG Findings in Patients with First Febrile UTI \\
\hline
\end{tabular}

Voiding cystourethrography (VCUG) was performed after a period of 1 month in those children who either had an abnormal ultrasonogram or evidence of acute pyelonephritis on initial DMSA or both. The findings are depicted in Figure 2.

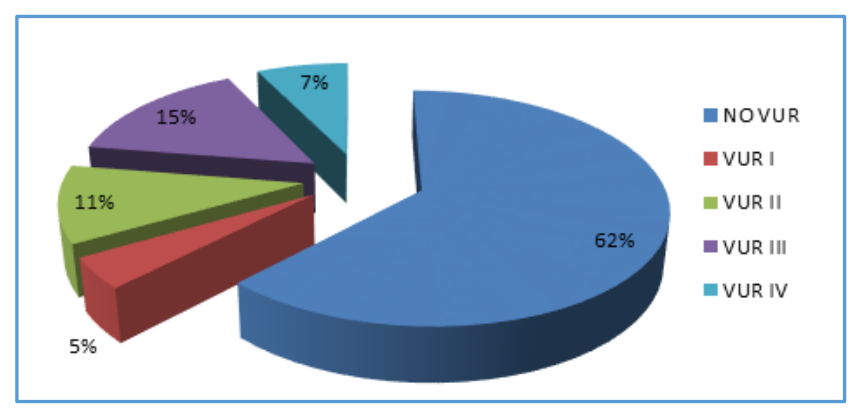

Figure 2. VCUG Findings in Patients in Terms of Renal Units

DMSA scan performed 6 months later showed scarring in 22 patients $(20.3 \%)$ of overall patients. All children whose initial scans were normal had normal scans at follow-up. $42.3 \%$ of the children with acute pyelonephritis (22/52) had evidence of renal scarring 6 months later.
The occurrence of renal scarring in different age groups is tabulated in Table 2. However, no significant relationship could be found ( $p$ value $>0.05$ ).

\begin{tabular}{|c|c|c|c|}
\hline Age in Months & No. of Patients & Renal Scarring & \% \\
\hline Up to 6 Months & 43 & 8 & 19 \\
\hline 7-12 Months & 20 & 6 & 30 \\
\hline 12-24 Months & 24 & 4 & 17 \\
\hline 24-36 Months & 21 & 4 & 19 \\
\hline \multicolumn{2}{|c|}{ Table 2 Age Related Renal Scarring } \\
\hline
\end{tabular}

Out of the total 69 patients who underwent VCUG, renal scarring was more likely to occur in children with documented VUR than those without VUR (17/39 vs. 5/30), p value $<0.017$. Among the patients with VUR, scarring was seen to occur more likely in patients with higher grades of VUR ( $p$ value $<0.001$ ) as depicted in Table 2, Figure 3.

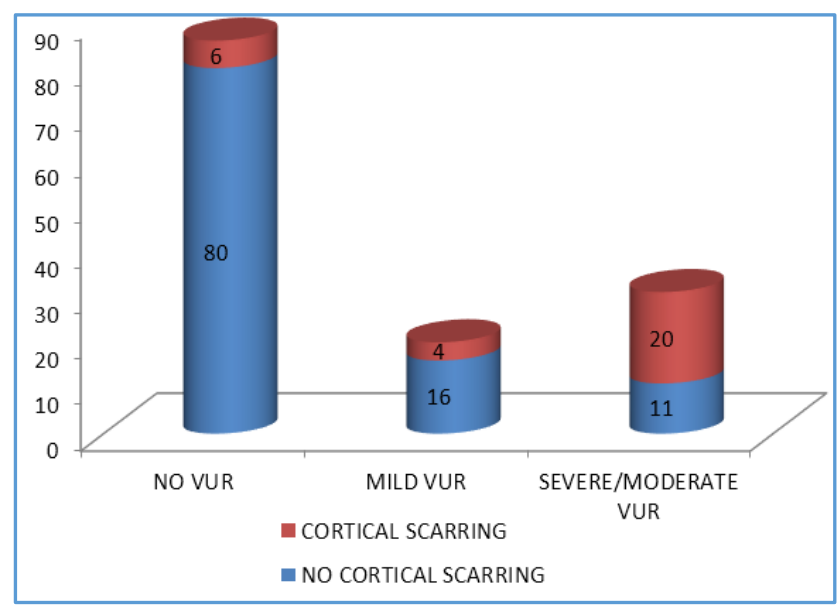

Figure 3. Relationship between Cortical
Scarring and VUR in Terms of Renal Units

\section{DISCUSSION}

Febrile UTI, in particular, is a widely researched topic because of the potential to cause renal scarring resulting in hypertension, preeclampsia, renal insufficiency and end-stage renal disease. Children suffering from UTI are frequently referred for various imaging studies including renal bladder ultrasonogram (RBUS), radionuclide 99-Technetium dimercaptosuccinic acid scan (DMSA), computed tomography (CT Scan) and magnetic resonance imaging (MRI) of urinary tract on an assumption that early detection of urological abnormalities will lead to improved outcomes. ${ }^{6}$ It is the endeavour of paediatric specialists throughout the world to reach an investigation and management protocol that is highly efficacious in preventing the complications of UTI and at the same time does not expose young kids to superfluous and invasive investigations. Our study is an attempt in this direction and it aspires to answer the queries surrounding UTI in children.

Being non-invasive, a renal ultrasonogram (RBUS) is often the first investigation done and was done in all our patients within the first week of diagnosis. Out of 108 patients, RBUS was normal in 63 (58\%) and abnormal in 45 (42\%). Sonograms showed changes consistent with acute pyelonephritis in $27.7 \%$ (30/ 108) of the whole group and in only $57.7 \%(30 / 52)$ of the patients with scintigraphically documented acute pyelonephritis. Poor sensitivity of RBUS in detection of pyelonephritis has been inferred by Bjorgvinsson 
et al, Foresman et al and Nguyen et al.7,8,9 Bjorgvinsson et al had ultrasonographic changes consistent with acute pyelonephritis in 24\% (22/91) of whole group. Foresman et al summarised that ultrasound findings during acute pyelonephritis do not correlate with and are not predictive of presence or grade of VUR on subsequent VCUG. Thus, we conclude that RBUS is not very sensitive for diagnosis of acute pyelonephritis in febrile UTI. Hydronephrosis of varying severity was detected in $37(34.2 \%)$ of our patients. However, as 39 patients did not undergo VCUG as per AAP guidelines, the usefulness of RBUS in detecting VUR could not be evaluated. High false positive rate of ultrasonography could be attributed to high frequency of E. coli UTI in our patients, which has been associated with dilatation of urinary tract in acute stage and can lead to erroneous interpretation of hydronephrosis as was reported by Alan S Peterson in 2012.10 The use of routine ultrasound in children in whom first febrile UTI is diagnosed can be of importance in finding patients with obstructive lesions in developing countries, where use of foetal ultrasonography is still limited. In this study, it was also noted that higher grade VUR (Grade 3 or 4) was more likely to occur among children with abnormal ultrasonographic findings than among those with normal findings $(28 / 63$ vs. $3 / 75$; $p$ value $<0.001)$. Similar findings were seen in a study published in 2003 by Hoberman et al in which vesicoureteral reflux of grade III or IV was more likely to occur among children with abnormal ultrasonographic findings than among those with normal findings $(p=0.02){ }^{11}$ Therefore, the benefit of RBUS in the armamentarium against febrile UTI appears to be its affordability and availability and its ability to detect higher grades of VUR; however, its utility in detecting pyelonephritis looks limited.

Scintigraphy was also done in our patients, both in the acute stage and after 6 months to detect renal scarring. DMSA was suggestive of acute pyelonephritis in $52(48 \%)$ patients in acute stage and of renal scarring in $22(20 \%)$ at 6 months. All patients who had scarring at 6 months had abnormal initial scan. USG findings were suggestive of pyelonephritis in only 30. All children whose initial scans were normal had normal scans at follow-up. Hoberman et al in a study published in 2003 demonstrated similar findings.11 Therefore, we conclude that DMSA appears to be the best available investigation for detection of acute pyelonephritis. It can also predict who is less likely to develop renal scarring in febrile UTI patients. Usefulness of DMSA scan in febrile UTI has been documented by other researchers as well11-19 and has been endorsed by AAP, who now recommend it in all children $<24$ months with first febrile UTI. However, routine use of this imaging during acute illness does not alter treatment in the majority of cases and it does not predict who exactly is going to develop scarring. The results of Hoberman et al suggested that in children two years of age or younger who have a first febrile urinary tract infection, the results of approximately 60 to 65 percent of imaging studies will be abnormal. On the assumption of a sensitivity of 85 to 90 percent, nearly 75 percent of young children with fever and clinically significant bacteriuria will have acute pyelonephritis. It may therefore be reasonable for the clinician to assume that nearly all such children have acute pyelonephritis. ${ }^{11}$

Only those patients whose ultrasonography or scanning revealed abnormalities were subjected to VCUG. In patients with acute pyelonephritis, patients with VUR were seen more likely to end up in renal scarring than those without VUR $(17 / 30$ vs. $5 / 22$; $p$ value $<0.022)$. Out of the total 69 patients who underwent VCUG, renal scarring was more likely to occur in children with documented VUR than those without VUR $(17 / 39$ vs. $5 / 30$; p value < 0.017$)$. Among the patients with VUR, scarring was seen to occur more likely in patients with higher grades of VUR ( $p$ value $<0.001$ ). Similar relationship of VCUG with scintigraphic abnormalities was found by Hoberman $\mathrm{A}$ et al and Ajdinović et al. ${ }^{11,20}$ Hoberman et al observed degree of vesicoureteral reflux was significantly associated with a higher incidence of renal scarring $(p=0.007) .11$ Though VUR is also an established important factor in genesis of renal scarring and thereafter hypertension and end stage renal disease, routine use of VCUG in febrile UTI has been questioned by many.3,17,18,19,21 However, further research is needed.

The overall incidence of renal scarring in this study was $20.3 \%$, which is lower than the 30 percent previously reported.22,23,24 The relatively low incidence observed in this study may have resulted from the active surveillance for and treatment of urinary tract infection in young children with fever. Compared to intravenous pyelography, the renal scintigram is very sensitive for detection of renal scarring in patients following acute pyelonephritis. Earlier studies demonstrated the sequelae of reflux nephropathy i.e. hypertension, renal insufficiency and end stage renal disease in a significant group of patients. ${ }^{25,26}$ But the method of detection used was intravenous pyelography, which was substantially less sensitive than technetium-99m labeled dimercaptosuccinic acid scanning and almost certainly identified children with extensive rather than minimal parenchymal damage. A study of women with scarring using DMSA confirmed that renal function was reasonably well preserved and that the incidence of hypertension was lower than had previously been reported. ${ }^{27}$

\section{CONCLUSION}

To conclude, the results of this study suggest that the renal ultrasound is of limited value in febrile UTI, especially at places where DMSA scanning is available which identifies patients with acute pyelonephritis who are at risk of development of renal scarring later in life. VCUG may also demonstrate a relationship between VUR and renal inflammation and identify high-risk group for development of renal scarring (Patients with high-grade VUR). However, the exact role of these modalities in evaluation and management of patients with first febrile UTI is still being debated and further studies are required in this regard.

\section{REFERENCES}

[1] Kliegman R, Nelson WE. Nelson textbook of pediatrics. Chapter - 532. 19th edn. Philadelphia: Saunders 2011.

[2] Prasad MM, Cheng EY. Radiographic evaluation of children with febrile urinary tract infection: bottomup, top-down, or none of the above? Article ID 716739, Advances in Urology 2012;2012:1-8.

[3] Juliano TM, Stephany HA, Clayton DB, et al. Incidence of abnormal imaging and recurrent pyelonephritis after first febrile urinary tract infection in children 224 months. J Urol 2013;190(40):1505-10. 
[4] Konda R, Sakai K, Ota S, et al. Ultrasound grade of hydronephrosis and severity of renal cortical damage on $99 \mathrm{~m}$ technetium dimercaptosuccinium acid renal scan in infants with ultrasound hydronephrosis during followup and after pyeloplasty. J Urology 2002;167(5):2159-63.

[5] Medical vs surgical treatment of primary vesicoureteral reflux: report of International Reflux Study Committee. Pediatrics 1981;67(3):392-400.

[6] Dick PT, Feldman W. Routine diagnostic imaging for childhood urinary tract infections: a systematic overview. J Pediatr 1996;128(1):15-22.

[7] Bjorgvinsson E, Majd M, Eggli KD. Diagnosis of acute pyelonephritis in children: comparison of sonography and 99mTc-DMSA scintigraphy. AJR Am J Roentgenol 1991;157(3):539-43.

[8] Foresman WH, Hulbert WC, Rabinowitz R. Does urinary tract ultrasonography at hospitalization for acute pyelonephritis predict vesicoureteral reflux? J Urol 2001;165(6 Pt 2):2232-4.

[9] Nguyen HT, Bauer SB, Peters CA, et al. $99 \mathrm{~m}$ Technetium dimercapto-succinic acid renal scintigraphy abnormalities in infants with sterile high grade vesicoureteral reflux. J Urol 2000;164(5):16749.

[10] Peterson AS. The Journal of Lancaster General Hospital. Spring 2012;7(1).

[11] Hoberman A, Charron M, Hickey RW, et al. Imaging studies after a first febrile urinary tract infection in young children. N Engl J Med 2003;348(3):195-202.

[12] Jakobsson B, Nolstedt L, Svensson L, et al. 99mTechnetium-dimercaptosuccinic acid scan in the diagnosis of acute pyelonephritis in children: relation to clinical and radiological findings. Pediatr Nephrol 1992;6(4):328-34.

[13] Jakobsson B, Soderlundh S, Berg U. Diagnostic significance of $99 \mathrm{~m}$ Tc-dimercaptosuccinic acid scintigraphy in urinary tract infection. Arch Dis Child 1992;67(11):1338-42.

[14] Kass EJ, Fink-Bennett D, Cacciarelli AA, et al. The sensitivity of renal scintigraphy and sonography in detecting non-obstructive acute pyelonephritis. J Urol 1992;148(2 Pt 2):606-8.

[15] Benador D, Benador N, Slosman DO, et al. Cortical scintigraphy in the evaluation of renal parenchymal changes in children with pyelonephritis. J Pediatr 1994;124(1):17-20.
[16] Biggi A, Dardanelli L, Pomero G, et al. Acute renal cortical scintigraphy in children with a first urinary tract infection. Pediatr Nephrol 2001;16(9):733-8.

[17] Preda I, Jodal U, Sixt R, et al. Normal dimercaptosuccinic acid scintigraphy makes voiding cystourethrography unnecessary after urinary tract infection. J Pediatr 2007;151(6):581-4.e1.

[18] Montini G, Zucchetta P, Tomasi L, et al. The value of imaging studies following after a first febrile urinary tract infection in young children: data from the IRIS-1 trial. Pediatrics 2009;123(2): e239-46.

[19] Lee JH, Kim MK, Park SE. Is a routine voiding cystourethrogram necessary in children after the first febrile urinary tract infection? Acta Paediatrica 2012;101(3):e105-9.

[20] Ajdinović B, Krstić Z, Dopuda M, et al. Renal scintigraphy in children with urinary tract infections. Vojnosanit Pregl 2005;62(10):745-9.

[21] Tsai JD, Huang CT, Lin PY, et al. Screening high-grade vesicoureteral reflux in young infants with a febrile urinary tract infection. Pediatr Nephrol 2012;27(6):955-63.

[22] Jakobsson B, Svensson L. Transient pyelonephritic changes on $99 \mathrm{~m}$ Technetium-dimercaptosuccinic acid scan for at least five months after infection. Acta Paediatr 1997;86(8):803-7.

[23] Rushton HG, Majd M, Jantausch B, et al. Renal scarring following reflux and non-reflux pyelonephritis in children: evaluation with $99 \mathrm{~m}$ technetiumdimercaptosuccinic acid scintigraphy. J Urol 1992;147(5):1327-32.

[24] Stokland E, Hellstrom M, Jacobsson B, et al. Renal damage one year after first urinary tract infection: role of dimercaptosuccinic acid scintigraphy. J Pediatr 1996;129(6):815-20.

[25] Jacobson SH, Eklof O, Eriksson CG, et al. Development of hypertension and uraemia after pyelonephritis in childhood: 27 year follow-up. BMJ 1989;299(6701):703-6.

[26] Jacobson SH, Eklof O, Lins LE, et al. Long-term prognosis of post-infectious renal scarring in relation to radiologic findings in childhood -- a 27-year followup. Pediatr Nephrol 1992;6(1):19-24.

[27] Martinell J, Lidin-Janson G, Jagenburg R, et al. Girls prone to urinary infections followed into adulthood: indices of renal disease. Pediatr Nephrol 1996;10(2):139-42. 